\title{
Detection of early pregnancy factor (EPF) using the rabbit ovary and oviduct perfused in vitro*
}

\author{
K. Sueoka, A. M. Dharmarajan, E. Michael, S. J. Atlas and E. E. Wallach \\ The Johns Hopkins University, School of Medicine, Department of Gynecology and Obstetrics, \\ 600 N. Wolfe Street, Baltimore, Maryland 21205, U.S.A.
}

\begin{abstract}
Summary. Two peaks of rabbit serum EPF activity were seen over the course of pregnancy. Rabbit ovaries with or without attached oviducts were perfused in vitro for $5 \mathrm{~h}$ beginning $12,16,24,48,72$ and $120 \mathrm{~h}$ after mating. Perfused isolated ovaries did not produce EPF in vitro, but significant EPF activity was detected in the perfusate of the ovary together with oviduct. Pseudopregnant animals and those rabbits that did not ovulate exhibited no perfusate EPF activity. Perfusate EPF activity was highest at the time embryos were at the pronuclear stage and continued through the morula stage. Although the location of embryos at $72 \mathrm{~h}$ after mating varied between oviduct and uterus, EPF activity was maintained over the perfusion period. The results suggest that EPF release occurs within $3 \mathrm{~h}$ of fertilization and that the presence of the preblastocyst embryo is crucial for EPF release.
\end{abstract}

Keywords: EPF; rabbit; perfusion; ovary; oviduct

\section{Introduction}

Early pregnancy factor (EPF) is a pregnancy-associated glycoprotein that may be useful for the very early detection of fertilization. EPF may also be involved in the immunobiology of implantation. EPF is first detected in the serum at $6 \mathrm{~h}$ after mating in the mouse (Morton et al., 1974, 1976), at $24 \mathrm{~h}$ after insemination in the pig (Nancarrow et al., 1981) and sheep (Rolfe, 1982), and at $48 \mathrm{~h}$ after insemination in woman (Morton et al., 1979, 1983). Two phases of EPF production have been found in each of these species despite the wide variation in length of pregnancy. Early EPF is produced during the preimplantation period in the presence of fertilized ova, and late EPF is produced beginning at implantation and continues through the middle third of the pregnancy. Morton et al. (1980), using medium from in-vitro organ culture, demonstrated that early EPF consists of two components: EPF-A, produced by the oviduct during oestrus and pregnancy, and EPF-B, produced by the ovary during pregnancy. The presence of fertilized ova and prolactin can stimulate production of EPF-B (Morton et al., 1980; Cavanagh et al., 1982). However, the time course of EPF production, the relationship to embryo development, and the role of the ovary and oviduct have yet to be determined. No data have been reported on EPF production in the rabbit. This study was designed to elucidate the time course and source of rabbit EPF production, using an in-vitro perfusion system consisting of both ovary and oviduct.

\section{Materials and Methods}

Animals. Sexually mature, virgin New Zealand White rabbits were used in all experiments. Female rabbits were isolated for a minimum of 3 weeks before the experimental procedure. Rabbits were caged individually under controlled temperature and light with free access to Purina Rabbit Chow and water. Each female was mated with a

*Reprint requests to: E. E. Wallach, M.D. 
sexually mature male rabbit at $12,16,24,48,72$ or $120 \mathrm{~h}$ before perfusion. Two control groups were prepared for comparison; a pseudopregnant group injected intravenously with 100 i.u. hCG (Pregnyl: Organon, West Orange, NJ, U.S.A.) $24 \mathrm{~h}$ before the perfusion, and an unstimulated group of rabbits that had been caged with males but appeared not to have mated (intact follicles, no oocytes or corpora lutea).

Ovary and oviduct perfusion procedure. Rabbits were anaesthetized with pentobarbitone sodium ( $32 \mathrm{mg} / \mathrm{kg})$, given heparin sulphate $(120 \mathrm{U} / \mathrm{kg})$ for anticoagulation, and then subjected to laparotomy. After ligation of collateral vessels and the utero-tubal junction, the ovarian artery and the vein were individually cannulated in situ (Fig. 1). For perfusion of the ovary + oviduct, each ovary with its vascular pedicle and attached oviduct was removed and placed in a perfusion chamber. For perfusion of the ovary alone, the tubal branch was ligated close to the bifurcation from the ovarian vessels, and the cannulation performed as in Fig. 1. The cannulated ovary without the oviduct was removed and perfused. The perfusion medium consisted of tissue culture Medium 199 (Whittaker M.A. Bioproducts, Walkerville, MD, U.S.A.) $150 \mathrm{ml} /$ ovary supplemented with heparin sulphate $(200 \mathrm{U} / \mathrm{l}$; Invenex Laboratories, Chagrin Falls, OH, U.S.A.), insulin (20 U/1; Squibb-Nova, Inc., Princeton, NJ, U.S.A.), streptomycin ( $50 \mathrm{mg} / \mathrm{l}$; Sigma Chemical Co., St Louis, MO, U.S.A.), and penicillin G $(75 \mathrm{mg} / 1$; Sigma), adjusted to a $\mathrm{pH}$ of $7 \cdot 4$. Perfusion of the ovary alone was performed to determine the role of the oviduct in EPF production. The arterial cannulation procedure and perfusion apparatus were as previously described (Lambertsen et al., 1976; Kobayashi et al., 1981). The vein was cannulated as described by Dharmarajan et al. (1988) and samples were taken from the cannulated vein each hour. The perfusion was carried out in a constant temperature room at $37^{\circ} \mathrm{C}$ for $5 \mathrm{~h}$.

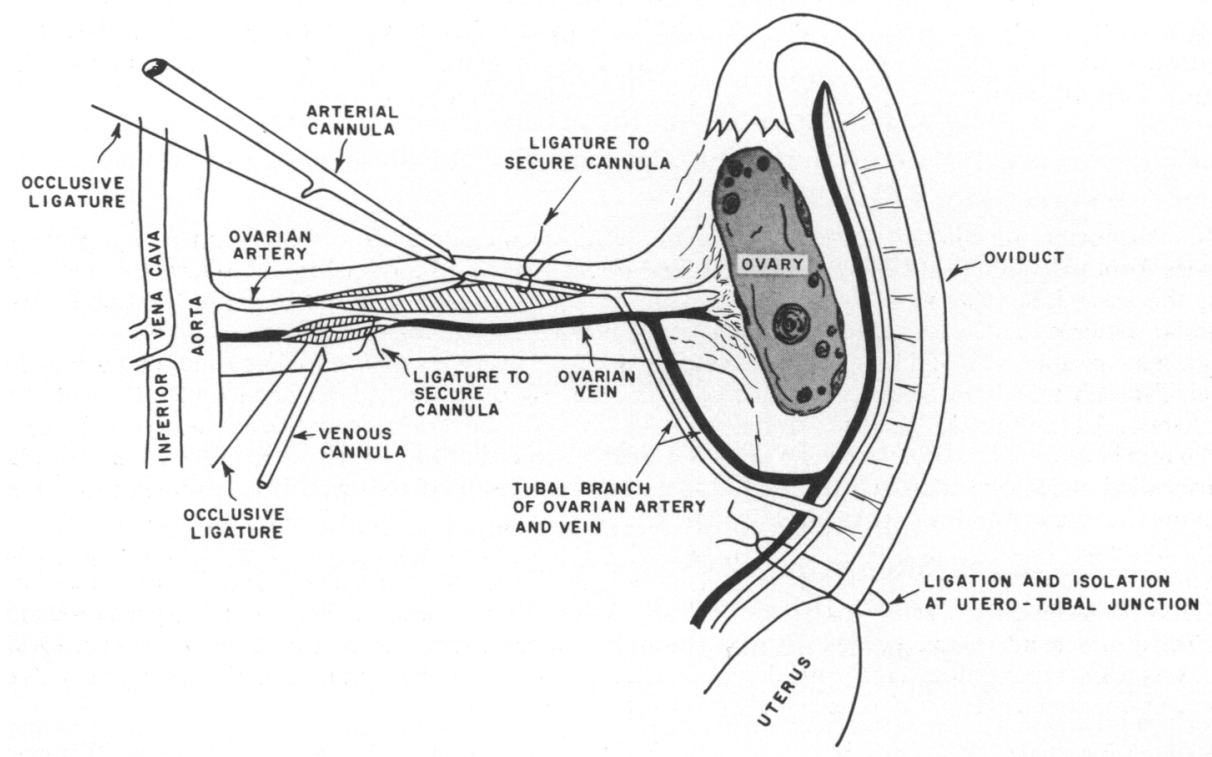

Fig. 1. Ovary plus oviduct preparation for perfusion.

Serum EPF samples. Blood samples were collected from the marginal ear vein at the end of the laparotomy in which the ovary was removed for perfusion. Serial blood samples were also collected over the course of pregnancy in another group of rabbits to examine the pattern of EPF production. The sera were separated and stored at $-30^{\circ} \mathrm{C}$ until EPF determination.

Embryo stage determination. After the 5-h perfusion, the oviducts were flushed with perfusion medium and the collected embryos were examined for developmental stage under phase-contrast microscopy ( $\times 40$ objective).

EPF assay. EPF was assayed by the rosette inhibition test, originally described by Bach \& Antonie (1968), and adapted for the assay of EPF by Morton et al. (1974). This test depends on the ability of EPF to enhance the inhibition of antilymphocyte serum of rosette formation between lymphocytes and heterologous red blood cells. The presence of EPF does not itself affect the number of rosettes formed, but increases the efficacy of rosette inhibition by antibody. The rosette inhibition test may not be species specific; the reaction between mouse spleen cells and human red blood cells is able to detect both mouse and human EPF activity (Rolfe et al., 1984). The rosette inhibition test has been modified to include the use of anti T-cell monoclonal antibody (Tinneberg et al., 1984; Rolfe et al., 1984) instead of antilymphocyte serum, and human peripheral lymphocytes instead of mouse spleen cells (Morton et al., 1977). In this study, active E-rosette formation (i.e. the reaction between human peripheral blood lymphocytes and sheep red blood 


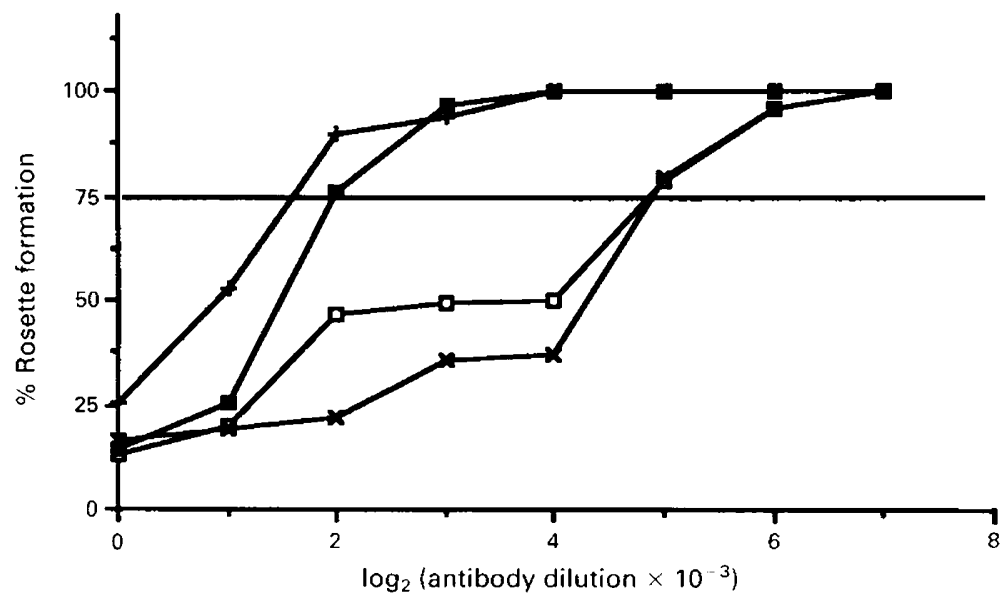

Fig. 2. Percentage E-rosette formation in the presence of dilutions of anti-T cell antibody in pregnant and non-pregnant human and rabbit sera. Each curve is from a single individual. Human serm, 6th week of pregnancy $(\square-\square)$; human serum, non-pregnant ( $\square-\square$ ); rabbit serum, $24 \mathrm{~h}$ after mating $(x-\times)$; rabbit serum, non-pregnant $(+-+)$.

cells (RBC) that forms immediately upon combining the cells) was measured. With this system, a high percentage of lymphocytes form rosettes and the mechanism of rosette formation is well-established. The curve for rosette formation using this assay is shown for both human and rabbit in Fig. 2. The inhibition of rosette formation by antibody shows similar patterns in these two species during pregnancy and in the non-pregnant state.

Human male peripheral blood lymphocytes were isolated by density gradient centrifugation with a Ficoll Paque (Pharmacia Fine Chemicals, Piscataway, NJ, U.S.A.) and $2.0 \times 10^{6}$ cells were incubated with $100 \mu 1$ of test sample at $37^{\circ} \mathrm{C}$ for $30 \mathrm{~min}$. All test samples had been stored at $-80^{\circ} \mathrm{C}$ for less than 3 months and were inactivated by heating at $56^{\circ} \mathrm{C}$ for $30 \mathrm{~min}$ before assay. After washing 3 times in Hanks' balanced salt solution (HBSS, Whittaker), lymphocytes were resuspended at $10^{7}$ cells $/ \mathrm{ml}$ and $20 \mu \mathrm{l}$ were distributed to each well of a 96-well U-bottom microplate (Falcon 3910, Becton Dickinson Labware, Lincoln Park, NJ, U.S.A.). Then $50 \mu$ l of anti-T cell antibody (OKT-11; Ortho Diagnostic Systems, Inc., Raritan, NJ, U.S.A.), diluted 1000- to 128000 -fold with HBSS, and $10 \mu l$ guinea-pig complement (Whittaker M.A. Bioproducts), absorbed by human and sheep red blood cells 3 times, were added to each well and the suspension was incubated at $37^{\circ} \mathrm{C}$ for $30 \mathrm{~min}$. Then $20 \mu \mathrm{l}$ of a sheep RBC suspension containing $1.5 \times 10^{8}$ cells $/ \mathrm{ml}$ were added to each well and the microplate was centrifuged at $250 \mathrm{~g}$ for 5 min for rosette formation. The pellet was transferred onto a slide stained with brilliant cresyl blue and the number of lymphocytes with rosette formation was counted using a $\times 40$ objective and converted to a percentage.

Rosette inhibition titre. The rosette inhibition titre (RIT) has been used to evaluate EPF activity. RIT equals the reciprocal of the highest dilution of antibody in which the number of rosettes formed was less than $75 \%$ of the control value: $\mathrm{RIT}=\log _{2}$ (reciprocal dilution of antibody $\times 10^{-3}$ ).

EPF activity in 10 non-pregnant rabbits was $1.0 \pm 0$ using OKT-11 (Figs 3 \& 6). In a more extensive series of assays with this system we have found that the average EPF activity in sera from 24 non-pregnant rabbits was $1.18 \pm 0.06$ (unpublished data) and in no case was RIT $\geq 3$. Therefore, an RIT of 3 or greater was considered positive for $\mathrm{EPF}$.

Statistical analysis. Student's $t$ test was used to compare serum and mean perfusate EPF activity. Perfusate EPF in the ovary \pm oviduct was analysed by the paired $t$ test. One-way analysis of variance (ANOVA) was used to examine serum and mean perfusate EPF activity over the course of early pregnancy. Differences with $P<0.05$ were considered significant.

\section{Results}

\section{Rabbit serum EPF during the course of pregnancy}

Figure 3 depicts mean serum EPF activity during the course of pregnancy in 4 rabbits. EPF activity was not detected in the serum of unstimulated rabbits or $12 \mathrm{~h}$ after mating (RIT $\leq 1$ ). The 


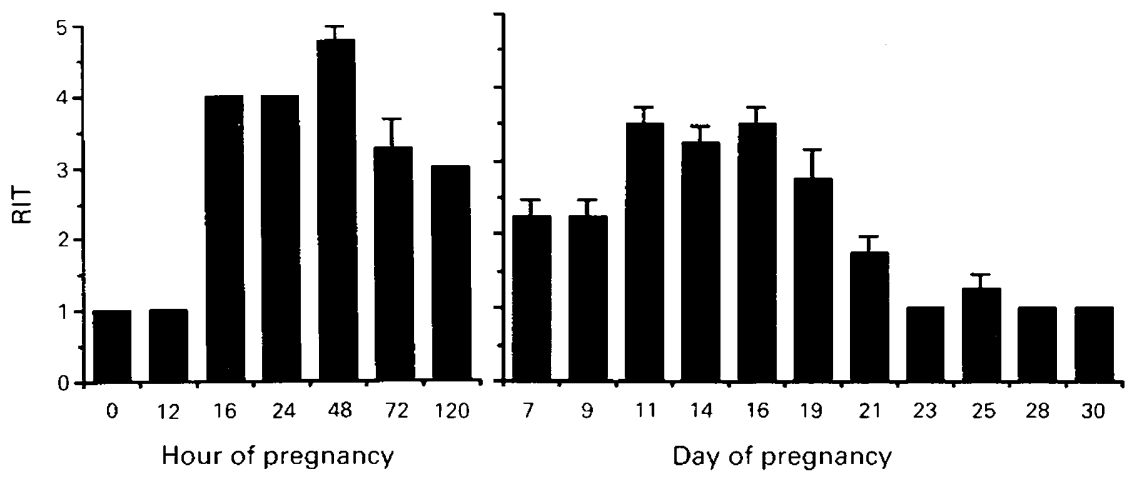

Fig. 3. Serum EPF values in 4 rabbits followed serially over the course of pregnancy (Day $0=$ day of mating, $0 \mathrm{~h}$ sample was taken just before mating). Values are mean \pm s.e.m.

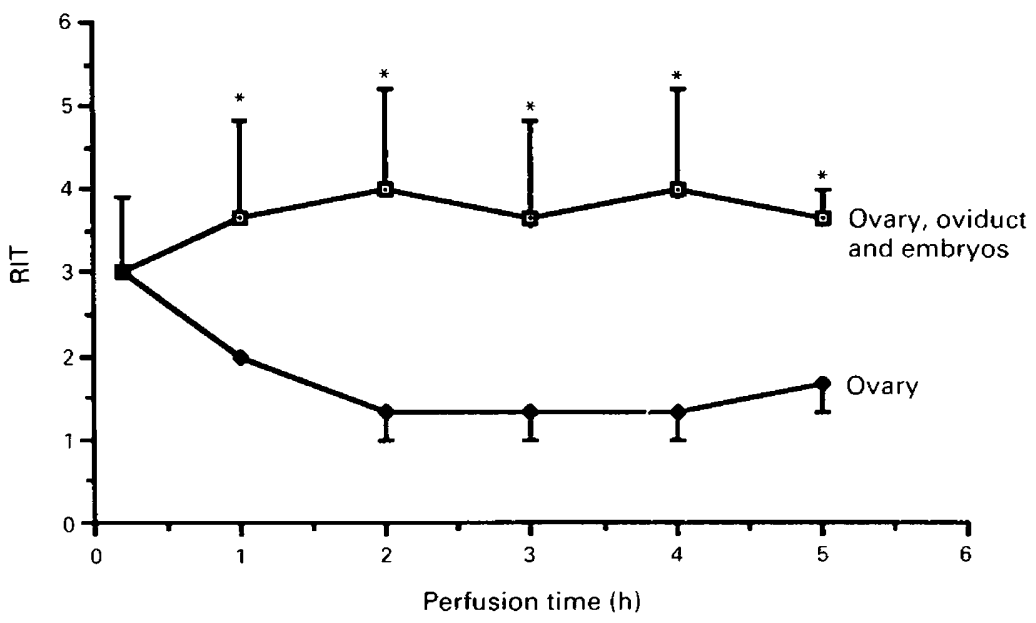

Fig. 4. Perfusate EPF as measured by RIT from the ovary vs the contralateral ovary + oviduct of the same animal. Values are means \pm s.e.m. for 3 rabbits. ${ }^{*} P<0.05$ compared with value for ovary alone.

serum EPF activity increased to the positive range (RIT $\geq 3$ ) $16 \mathrm{~h}$ after mating. Two peaks of EPF activity were seen, as has been reported for every species examined. Early EPF was detected $24-120 \mathrm{~h}$ after mating, and then EPF activity declined into the negative range (RIT $<3$ ) on Day 7 (day of mating = Day 0 ). The second peak was seen beginning on Day 11 , and its activity was maintained until Day 16. Thereafter, EPF activity decreased to the negative range by Day 19 and reached the basal level by Day 25 .

\section{EPF activity in the perfusate of ovaries perfused with or without the oviduct}

The results of the two different types of perfusion are depicted in Fig. 4. The perfusate from the ovary plus oviduct maintained an RIT level of $\geq 3$ during the entire perfusion period. However, even though the perfusate of the ovary alone had the same EPF activity as did that of the ovary plus 


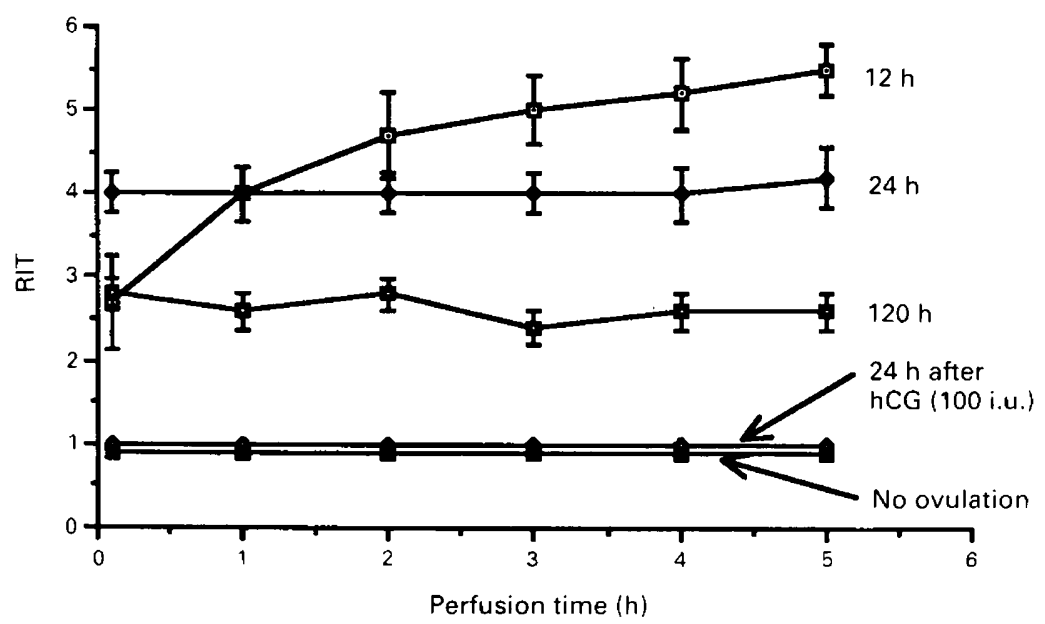

Fig. 5. EPF activity during perfusion performed at different times after mating. Non-pregnant controls are shown for comparison. Values are mean \pm s.e.m. for 2 perfusions from each of 3 rabbits.

oviduct at the onset of perfusion, this activity rapidly decreased to baseline levels. The difference in EPF activity between these two groups was significant $(P<0.05)$ except at time 0 . All subsequent perfusions were carried out using a preparation which included both ovary and oviduct.

\section{Changes in perfusate EPF activity after mating}

The perfusate EPF activity of the ovary plus oviduct with reference to time after mating is presented in Fig. 5. Two control groups are shown for comparison; a pseudopregnant group $24 \mathrm{~h}$ after hCG administration, and a group that did not ovulate. There was no EPF activity $(\mathrm{RIT}=1)$ in either of the two control groups. At the onset of perfusion, the perfusate of the group examined $12 \mathrm{~h}$ after mating contained no EPF activity. However, EPF activity was positive in the 1-h samples and it increased steadily for $5 \mathrm{~h}$. The group examined $16 \mathrm{~h}$ after mating followed a pattern similar to that of the 12-h group although the activity was lower (data not shown). By $24 \mathrm{~h}$ after mating, EPF activity was high at the onset of perfusion, and this activity was maintained over the perfusion period. By $120 \mathrm{~h}$ after mating, mean RIT was $<3$, and did not rise during the 5-h perfusion.

\section{EPF activity in serum and perfusate}

The results illustrated in Fig. 5 were used to calculate a mean perfusate RIT value over the 5-h perfusion for each stage of pregnancy. A comparison between serum, obtained immediately after laparotomy, and mean perfusate EPF activity for each stage of pregnancy is shown in Fig. 6. EPF activity was not detected in serum at $12 \mathrm{~h}$ after mating, while perfusate EPF activity was maximum at that time. EPF activity in serum reached that of perfusate at $16 \mathrm{~h}$ and thereafter remained higher. In contrast, perfusate EPF activity decreased gradually during the course of pregnancy, and RIT was $<3$ at $120 \mathrm{~h}$ after mating. Serum EPF activity in the groups $16-120 \mathrm{~h}$ after mating and perfusate EPF activity of all groups was significantly different from that of the control groups. The difference in EPF activity between perfusate and serum was not significant throughout the period examined except at $12 \mathrm{~h}$ after mating. 


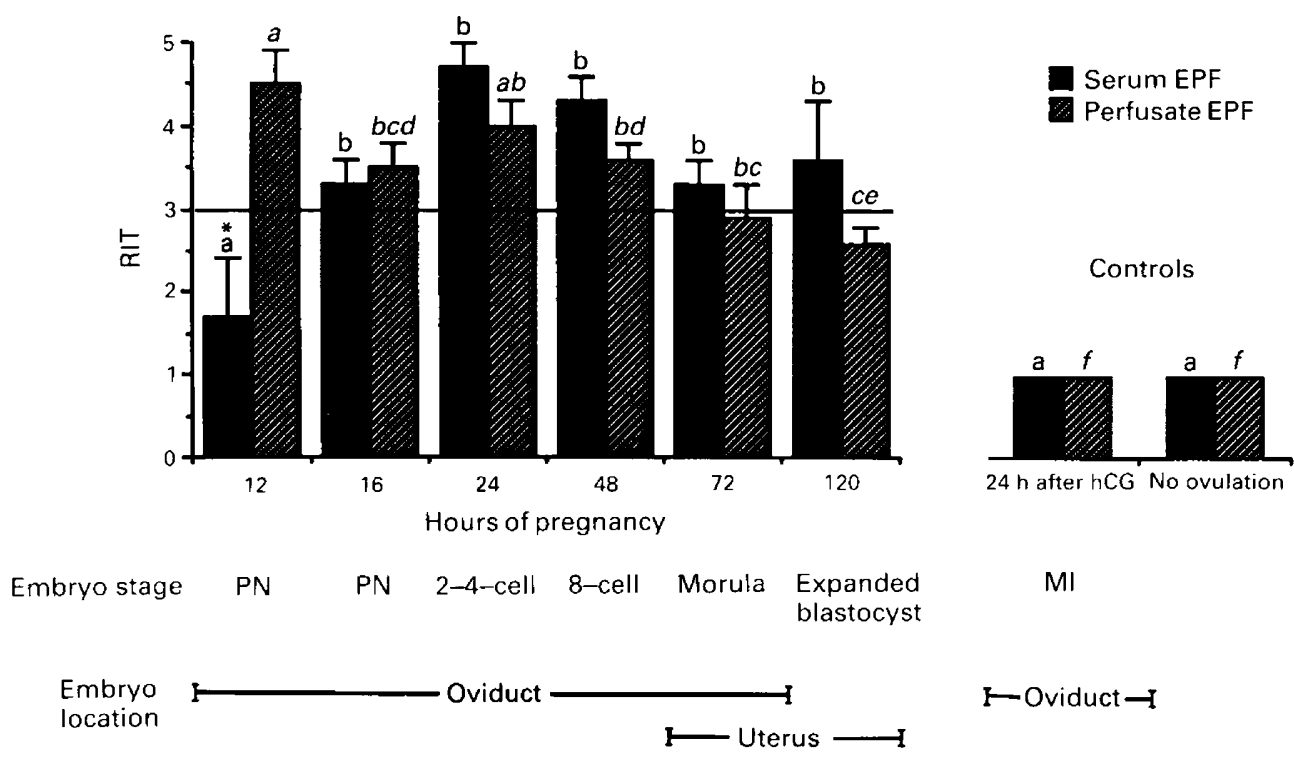

Fig. 6. EPF activity in the serum and perfusate, and embryo stage and location at different times after mating in rabbits. Two non-pregnant control groups are included for comparison. $\mathrm{PN}=$ pronuclear stage embryos; $\mathrm{MI}=$ metaphase I stage ova. ${ }^{*} P<0.05$ compared with perfusate EPF value at this time. Values (mean \pm s.e.m.) with different superscripts (roman letters for serum, italic for perfusate) are significantly different $(P<0.05)$.

Embryo developmental stage and location are also shown in Fig. 6. Note that all ova and embryos were examined after $5 \mathrm{~h}$ of perfusion, so that their age equals the time under consideration plus $5 \mathrm{~h}$. Pronuclear stage ova were seen in the oviduct 12 and $16 \mathrm{~h}$ after mating. At $24 \mathrm{~h}$ mostly 2-cell $(n=19)$ and some 4-cell $(n=4)$ embryos were found in the oviduct. At $48 \mathrm{~h}$ all embryos were at the 8-cell stage and were found in the oviduct. Morula-stage embryos were found in the oviducts ( 1 rabbit) or uterine horns ( 2 rabbits) at $72 \mathrm{~h}$ after mating. Serum and perfusate EPF activity in the 72 - $\mathrm{h}$ group remained in the positive range over the $5 \mathrm{~h}$ of perfusion for all rabbits. Expanded blastocyst embryos were found only in the uterus at $120 \mathrm{~h}$.

\section{Discussion}

The two peaks of activity found for rabbit serum EPF parallel the pattern of EPF activity described for other species (human: Morton et al., 1977, Smart et al., 1982; sheep: Morton et al., 1979; pig: Morton et al., 1983). This observation is especially striking when the wide variation in length of gestation among the various species is considered. Rabbit ovulation characteristically occurs at about $10 \mathrm{~h}$ after mating (Chang, 1955; Brackett et al., 1972). Detection of serum early EPF activity was estimated to be within $6 \mathrm{~h}$ of fertilization, when the fertilized ova were at the pronuclear stage. These results suggest that EPF may be a useful indicator of preimplantation pregnancy.

The apparent discrepancy in time of peak serum EPF activity seen in Figs 3 and 6 may be due to differences in the protocols. The data illustrated in Fig. 3 were derived from serial samples collected from unanaesthetized animals over the course of pregnancy, while those of Fig. 6 were from individual rabbits at the end of laparotomy. These animals were anaesthetized with pentobarbitone, treated with heparin, and subjected to surgical stress. 
The remainder of the experiments focused on the production of early EPF activity, determined both in serum and in the effluent of isolated perfused organs. The role of the oviduct in the production of early EPF is not yet clear. The perfused ovary did not produce EPF activity in the absence of the oviduct and embryos contained therein. The results of perfusate EPF determinations suggest that the oviduct and embryos may both be involved in production of EPF in the rabbit.

From the perfusate experiments, it would appear that EPF production begins within $3 \mathrm{~h}$ of fertilization and reaches detectable concentrations in the serum $3 \mathrm{~h}$ later. Clearance of EPF from serum may be a slow process and so serum concentrations are higher than perfusate values $24-120 \mathrm{~h}$ after mating.

EPF production decreases with time after mating as the embryo develops, but remains positive through the morula stage. At this time ( $72 \mathrm{~h}$ after mating) in some cases all embryos were already in the uterus and perfusions were performed in the absence of embryos. EPF activity was positive and stable over the 5-h perfusion period, confirming that embryo stage, and not location, is critical for triggering EPF production. A similar triggering factor has been observed for the mouse (Cavanagh et al., 1982). These results suggest that a triggering factor, released from the pronucleus to morula-stage embryo, is necessary to initiate, but not to maintain, EPF production by the ovary and oviduct.

We thank Dr Norman H. Dubin for valuable suggestions; Dr Caleb A. Awoniyi for preparation of figures; and Fran Karas for assistance in preparation of the manuscript. This work was supported by the Lalor Foundation.

\section{References}

Bach, J.F. \& Antoine, B. (1968) In vitro detection of immunosuppressive activity of anti-lymphocyte sera. Nature, Lond. 217, 658-659.

Brackett, B.G., Mills, J.A. \& Jeitles, G.G. (1972) In vitro fertilization of rabbit ova recovered from ovarian follicles. Fert. Steril. 23, 898-909.

Cavanagh, A.C., Morton, H., Rolfe, B.E. \& Gidley-Baird, A.A. (1982) Ovum factor: a first signal of pregnancy? Am. J. Reprod. Immunol. 2, 97-101.

Chang, M.C. (1955) The maturation of rabbit oocytes in culture and their maturation, activation, fertilization and subsequent development in the fallopian tubes. $J$. exp. Biol. 48, 379-405.

Dharmarajan, A.M., Yoshimura, Y., Sueoka, K., Atlas, S.J., Dubin, N.H., Ewing, L.L., Zirkin, B. \& Wallach, E.E. (1988) Progesterone secretion by corpora lutea of the isolated perfused rabbit ovary during pseudopregnancy. Biol. Reprod. 38, 1137-1143.

Kobayashi, Y., Wright, K.H., Santulli, R. \& Wallach, E.E. (1981) Ovulation and ovum maturation in the rabbit ovary perfused in vitro. Biol. Reprod. 24, 483-490.

Lambertsen, C.J., Jr, Greenbaum, D.F., Wright, K.H. \& Wallach, E.E. (1976) In vitro studies of ovulation in the perfused rabbit ovary. Fert. Steril. 27, 178-187.

Morton, H., Hegh, V. \& Clunie, G.J.A. (1974) Immunosuppression detected in pregnant mice by rosette inhibition test. Nature, Lond. 249, 459-460.

Morton, H., Hegh, V. \& Clunie, G.J.A. (1976) Studies of the rosette inhibition test in pregnant mice: evidence of immunosuppression? Proc. R. Soc. Lond. B 193, 413-419.

Morton, H., Rolfe, B.E., Clunie, G.J.A., Anderson, M.J. \& Morrison, J. (1977) An early pregnancy factor detected in human serum by the rosette inhibition test. Lancet i, 394-397.
Morton, H., Nancarrow, C.D., Scaramuzzi, R.J., Evison, B.M. \& Clunie, G.J.A. (1979) Detection of early pregnancy in sheep by the rosette inhibition test. $J$. Reprod. Fert. 56, 75-80.

Morton, H., Rolfe, B.E., McNeill, L., Clarke, F.M. \& Clunie, G.J.A. (1980) Early pregnancy factor: tissues involved in its production in the mouse. J. Reprod. Immunol. 2, 73-82.

Morton, H., Morton, D.J. \& Ellendorff, F. (1983) The appearance and characteristics of early pregnancy factor in the pig. $J$. Reprod. Fert. 68, 437-446.

Nancarrow, C.D., Wallace, A.L.C. \& Grewal, A.S. (1981) The early pregnancy factor of sheep and cattle. $J$. Reprod. Fert. Suppl. 30, 191-199.

Rolfe, B.E. (1982) Detection of fetal wastage. Fert. Steril. 37, 655-660.

Rolfe, B.E., Cavanagh, A.C., Forde, C., Bastin, F., Chen, C. M Morton, H. (1984) Modified rosette inhibition test with mouse lymphocytes for detection of early pregnancy factor in human pregnancy serum. $J$. Immunol. Meth. 70, 1-11.

Smart, Y.C., Roberts, T.K., Fraser, I.S., Cripps, A.W. \& Clancy, R.L. (1982) Validation of the rosette inhibition test for the detection of early pregnancy in women. Fert. Steril. 37, 779-785.

Tinneberg, H.R., Staves, R.P. \& Semm, J. (1984) Improvement of the rosette inhibition assay for the detection of early pregnancy factor (EPF) in humans using the monoclonal antibody, anti-human-Lyt-3. Am. J. Reprod. Immunol. 5, 151-6. 